\title{
PENGARUH LIQUIDITY, LEVERAGE, DAN EFFICIENCY TERHADAP PROFITABILITY PADA PERUSAHAAN SEKTOR CONSUMER GOODS
}

\author{
Welly dan Indra Widjaja \\ Program Studi Manajemen Fakultas Ekonomi Universitas Tarumanagara, Jakarta \\ Email: Wellyy1910@gmail.com
}

\begin{abstract}
Abstrak: Penelitian ini memiliki tujuan antara lain untuk mengetahui pengaruh current ratio, debt to total assets, dan total assets turnover terhadap profitability pada perusahaan manufaktur sektor consumer goods yang terdaftar di Bursa Efek Indonesia (BEI) periode 20152019. Pada penelitian ini sampel terdiri dari 27 sampel menggunakan purposive sampling dimana data diperoleh dari situs resmi Bursa Efek Indonesia yakni www.idx.co.id dan www.idnfinancial.com. Pengelolaan data menggunakan Eviews 9. Hasil penelitian ini menunjukkan bahwa debt to total assets memiliki pengaruh yang signifikan dan positif terhadap return on equity (ROE). Current ratio memiliki pengaruh positif tetapi tidak signifikan terhadap return on equity (ROE). Sedangkan total assets turnover memiliki pengaruh yang negatif dan tidak signifikan terhadap return on equity (ROE).
\end{abstract}

Kata Kunci: Current Ratio (CR), Debt to total assets (DAR), Efficiency (TATO), Profitability (ROE).

\begin{abstract}
The purpose of this research is to understand the impact of current ratio, total assets and total assets turnover towards profitability for the consumer goods manufacturers that were listed in Indonesia Stock Exchange in the year 2015-2019. This particular research took 27 samples by using purposive sampling where all the data were obtained from the official Indonesia stock exchange sites; $\underline{w w w . i d x . c o . i d}$ dan $\underline{w w w . i d n f i n a n c i a l . c o m}$. Additionally, the data management also utilizes Eviews 9 as well. The results of this research show that debt to total assets have a positive significant impact on return on equity (ROE). On the other hand, Current ratio has a positive impact but, it did not significantly impact the return on equity (ROE). Meanwhile, the total assets turnover has a negative impact, but it also did not significantly impact the return on equity $(R O E)$.
\end{abstract}

Keywords: Current Ratio (CR), Debt to total assets (DAR), Efficiency (TATO), Profitability (ROE).

\section{LATAR BELAKANG}

Menurut Yazdanfar (2013), perusahaan dipengaruhi secara signifikan oleh profitabilitas guna mencapai keuntungan serta keberlangsungan hidup perusahaan dalam jangka panjang. Seberapa besar laba bersih atau keuntungan pada perusahaan setelah dipotong dengan pajak dan modal sendiri dapat digambarkan melalui Return on Equity (ROE).

Perusahaan pada dasarnya memperoleh keuntungan semaksimal mungkin dari berbagai sumber pendanaan, dukungan pendanaan dapat berupa suntikan dana dari berbagai investor, serta pada dasarnya perusahaan membutuhkan pihak kreditor sebagai penyumbang dana, agar perusahaan dapat mendapatkan dana walaupun bersifat hutang agar dapat menjalankan aktivitas pada perusahaan, yang diukur dengan menggunakan debt to total assets ratio. Ketika perusahaan mendapatkan dana melalui utang maka rasio likuiditas akan mejelaskan berapa besar tingkat kemampuan pada suatu perusahaan untuk membayar kewajiban utang secara 
jangka pendek melalui aktiva perusahaan dengan menggunakan current ratio. Mengelola aktiva dalam perusahaan secara efisien agar dapat menghasilkan aliran kas masuk, dapat diukur dengan rasio aktivitas.

Pada saat ini Indonesia masuk sebagai negara yang memiliki jumlah dan peningkatan penduduk yang besar diikuti dengan peningkatan konsumsi domestik yang ikut meningkat juga. Peningkatan ini akan sangat berpengaruh terhadap industri consumer goods di Indonesia serta mempermudah menjangkau area pembeli yang lebih besar dan luas (beritasatu.com). Oleh sebab itu penelitian ini membatasi sektor perusahaan manufaktur yang hendak diteliti, pada sektor consumer goods.

Sehingga dari hasil pemaparan latar belakang tersebut peneliti memutuskan untuk melakukan penelitian berjudul "Pengaruh Rasio Liquidity, Leverage, Dan Efficiency Terhadap Profitability Pada Perusahaan Manufaktur Sektor Consumer Goods Yang Terdaftar Di Bursa Efek Indonesia Periode 2015-2019”.

\section{KAJIAN TEORI}

\section{Gambaran Umum Teori}

Teori yang dibahas pada penelitian ini adalah Teori Keagenan, Trade-Off Theory, Teori Sinyal. Teori Keagenan timbul disebabkan karna perbedaan penggunaan kewenangan dari agent dan principal yang nyatanya memiliki tujuan berbeda satu sama lain, Trade-Off Theory berasumsi bilamana hutang memiliki suatu manfaat yang lebih besar dan dapat menutup beban-beban yang harus dibayar oleh suatu perusahaan, maka perusahaan akan selalu melakukan pinjaman pendanaan berupa hutang agar keberlangsungan hidup pada suatu perusahaan dapat terus berjalan, sedangkan Teori Sinyal bertujuan untuk mengetahui perkembangan yang di alami oleh suatu perusahaan.

\section{Definisi Konseptual Variabel}

Profitabilitas yakni sebagai pengukur kinerja pada suatu perusahaan, perusahaan dinyatakan baik apabila perusahaan dapat mengelola serta memperoleh keuntungan, sedangkan sebaliknya perusahaan dinyatakan tidak baik apabila perusahaan tidak dapat mengelola atau memperoleh keuntungan untuk perusaahan itu sendiri berdasarkan dari penjualan perusahaan, total aktiva, dan modal yang dimiliki oleh perusahaan tersebut, return on equity merupakan perhitungan profitabilitas melalui pembagian laba bersih dengan total ekuitas.

Liquidity (Current Ratio) merupakan salah satu indikator untuk menghitung likuiditas serta digunakan oleh setiap perusahaan untuk mengetahui apakah aktiva lancar pada perusahaan mampu memenuhi sekaligus menutupi kewajiban lancar pada perusahaan.

Leverage (Debt to Total Assets) adalah rasio yang digunakan oleh perusahaan yang sumber pendanaan atau modal yang didapat berasal dari pihak luar perusahaan agar perusahaan dapat membiayai aktivanya, semakin besar debt to total assets maka semakin besar juga tingkat ketergantungan perusaahaan terhadap pihak luar serta semakin besar pula tingkat hutang yang wajib dibayar oleh perusahaan.

Efficiency (Total Assets Turnover) bertujuan agar perusahaan dapat mengetahui seberapa efektif perusahaan dalam menggunakan seluruh aktiva untuk menghasilkan penjualan, semakin tinggi total assets turnover yang digunakan oleh perusahaan maka semakin tinggi juga penjualan yang dihasilkan oleh perusahaan dan juga semakin efektif penggunaan aktiva yang dilakukan oleh perusahaan.

\section{Hubungan Antar Variabel}

Current ratio atau kerap disebut likuiditas merupakan salah satu faktor yang dapat mempengaruhi profitabilitas. Menurut Latha dan Rao (2017:1266) berpendapat bahwa semakin 
sedikit likuiditas yang didapatkan oleh perusaahaan berarti investasi yang diterima oleh perusahaan dinyatakan menurun, oleh sebab itu hal ini akan mempengaruhi profitabilitas pada suatu perusahaan.

Migliardo dan Schiliro (2016) yang terdapat dalam Myers (2001:136) menyatakan bahwa leverage merupakan suatu penentu dimana adanya pengaruh struktur modal terhadap kinerja perusahaan, leverage atau debt to total assets ratio mempengaruhi agency cost sehingga mengakibatkan timbulnya pengaruh terhadap profitabilitas pada perusahaan.

Suatu perusahaan ingin memperoleh suatu keuntungan yang tinggi biasanya berlandaskan pada efficiency. Menurut Pervan dan Mlikota (2012:281) mengatakan bahwa perputaran aset atau kerap disebut assets turnover juga memiliki dampak terhadap profitabilitas perusahaan, rasio assets turnover yang tinggi lebih memiliki dampak yang baik juga untuk perusahaan serta penambahan rasio assets turnover yang lebih tinggi melambangkan kekayaan pemegang saham yang lebih besar.

\section{Penelitian Relevan}

Waleed, et al (2016) dalam penelitiannya menyatakan bahwa liquidity memiliki pengaruh yang signifikan terhadap return on equity (ROE). Menurut Janjua, et al (2016) menyatakan bahwa current ratio memiliki pengaruh yang positif signifikan terhadap profitabilitas. Latha dan Rao (2017) menyatakan bahwa assets turnover memiliki pengaruh yang negatif serta signifikan terhadap profitabilitas, namun liquidity memiliki hubungan yang negatif dan tidak signifikan terhadap profitabilitas. Pervan dan Mlikota (2012) menyatakan bahwa asets turnover tidak memiliki pengaruh terhadap profitabilitas. Harisa, et al (2019) menyatakan bahwa leverage tidak memiliki pengaruh terhadap profitabilitas. AlAli, et al (2019) menyatakan jika leverage memiliki pengaruh yang signifikan terhadap profitabilitas.

\section{Hipotesis}

H1: Current Ratio memiliki pengaruh terhadap Profitabiliy.

H2: Debt to Total Assets memiliki pengaruh terhadap Profitability.

H3: Total Assets Turnover Ratio memiliki pengaruh terhadap Profitability.

\section{Gambar 1. Kerangka Pemikiran}

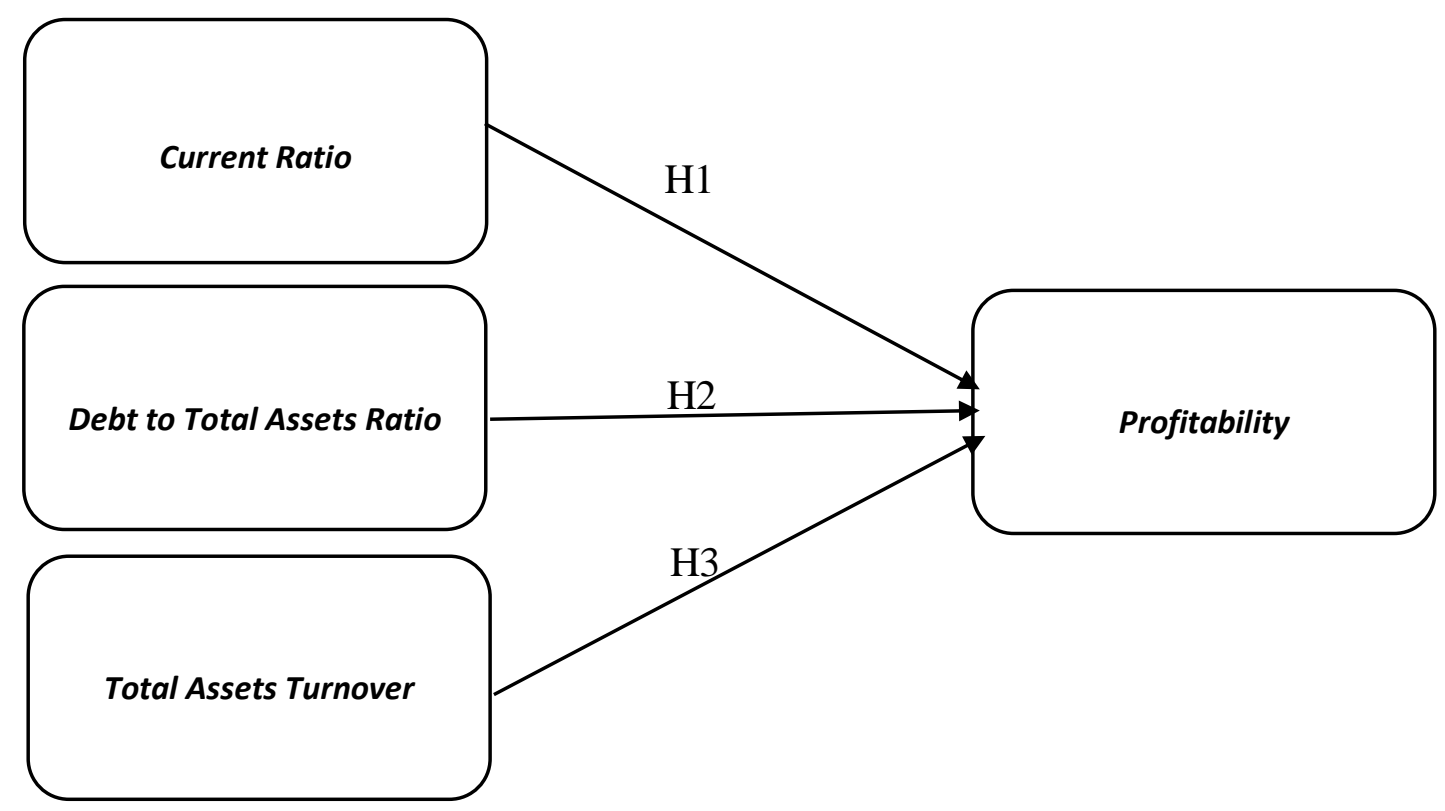




\section{METODOLOGI}

Pada penelitian ini penulis menggunakan metode kuantitatif, serta desain penelitian bersifat deskriptif. Penelitian ini menggunakan data panel yang merupakan gabungan antara data time series dan cross-section. Pada penelitian ini terdapat tiga variabel bebas sebagai penguji yakni current ratio, debt to total assets ratio, dan total assets turnover ratio serta satu variabel terikat yakni profitabilitas, data yang akan digunakan pada penelitian ini diambil dari laporan keuangan perusahaan manufaktur sektor consumer goods yang terdaftar di BEI (Bursa Efek Indonesia) dari tahun 2015-2019. Teknik yang digunakan pada penelitian ini adalah nonprofitability dengan metode purposive sampling. Sumber data berasal dari www.idx.co,id dan www.idnfinancials.com serta penganalisaan dan pengujian data menggunakan program Eviews 9. Ditemukan 58 perusahaan manufaktur yang bergerak disektor consumer goods, berdasarkan kriteria serta dilakukannya teknik purposive sampling maka ditemukan 27 perusahaan yang dijadikan sebagai sampel penelitian ini. Data dikumpulkan menggunakan Microsoft Excel, kemudian diolah menggunakan program Eviews 9.

\section{Hasil Analisis Data \\ Hasil Uji Multikolinearitas}

Tabel 1. Hasil Uji Multikolinearitas

\begin{tabular}{cccc} 
& CR & DAR & TATO \\
\hline \hline CR & 1.000000 & -0.676329 & -0.024501 \\
DAR & -0.676329 & 1.000000 & 0.011647 \\
TATO & -0.024501 & 0.011647 & 1.000000 \\
Sumber data: Hasil didapat menggunakan Eviews 9 &
\end{tabular}

Dari hasil uji multikolinearitas dapat dilihat bahwa tidak adanya hubungan atau korelasi antara variabel-variabel independen yang meliputi current ratio (CR), debt to total assets ratio (DAR), dan total assets turnover (TATO), sebab rasio yang dihasilkan antar variabel-variabel independen tidak > 0,8 (besar dari 0,8).

\section{Hasil Analisis Statistik Deskriptif}

Tabel 2. Hasil Analisis Statistik Deskriptif

\begin{tabular}{lcccc} 
& ROE & CR & DAR & TATO \\
\hline \hline Mean & 0.240583 & 2.945909 & 0.400935 & 1.182903 \\
Median & 0.164948 & 2.428285 & 0.368069 & 1.111807 \\
Maximum & 2.244585 & 8.637842 & 0.933230 & 3.104760 \\
Minimum & -0.379804 & 0.127207 & 0.070740 & 0.484484 \\
Std. Dev. & 0.365607 & 1.940003 & 0.190768 & 0.540084 \\
Skewness & 2.750578 & 1.013695 & 0.301491 & 1.314369 \\
Kurtosis & 11.66140 & 3.362458 & 2.190711 & 4.836021
\end{tabular}




$\begin{array}{lcccc}\text { Jarque-Bera } & 592.2145 & 23.85948 & 5.729265 & 57.83196 \\ \text { Probability } & 0.000000 & 0.000007 & 0.057004 & 0.000000 \\ \text { Sum } & 32.47876 & 397.6977 & 54.12627 & 159.6919 \\ \text { Sum Sq. Dev. } & 17.91162 & 504.3242 & 4.876567 & 39.08660 \\ & & & & 135\end{array}$

Sumber data: Hasil didapat menggunakan Eviews 9

\title{
Hasil Uji Chow
}

\author{
Tabel 3. Hasil Uji Chow
}

\begin{tabular}{lrrr} 
Redundant Fixed Effects Tests & & & \\
Equation: Untitled \\
Test cross-section fixed effects \\
\hline \hline Effects Test & Statistic & d.f. & Prob. \\
\hline \hline Cross-section F & 11.006454 & $(26,105)$ & 0.0000 \\
Cross-section Chi-square & 177.548800 & 26 & 0.0000 \\
\hline \hline
\end{tabular}

Sumber data: Hasil pengolahan menggunakan Eviews 9

Dari tabel hasil uji chow dapat dilihat bahwa nilai profitabilitas cross-section (Chisquare) sebesar 0,0000 yang dapat disimpulkan bahwa nilai tersebut $<0,05$ atau lebih kecil dari 0,05 sehingga dinyatakan bahwa $\mathrm{H}_{0}$ ditolak. Hal ini berarti fixed effects model merupakan model yang digunakan pada penelitian ini untuk melakukan estimasi terhadap data panel terkait.

\section{Hasil Uji Hausman}

\section{Tabel 4. Hasil Uji Hausman}

\begin{tabular}{|c|c|c|c|}
\hline Test Summary & $\begin{array}{l}\text { Chi-Sq. } \\
\text { Statistic }\end{array}$ & Chi-Sq. d.f. & Prob. \\
\hline Cross-section random & 14.641436 & 3 & 0.0022 \\
\hline
\end{tabular}

Sumber data: Hasil pengelolahan menggunakan Eviews 9

Dari data tabel diatas dapat diperhatikan bahwa nilai profitability Chi-square berada pada angka 0,0022 artinya $<0,05$ atau kecil dari 0,05 sehingga dapat ditarik kesimpulan bahwa $\mathrm{H}_{0}$ ditolak, sehingga model yang digunakan pada penelitian ini menggunakan model fixed effects model. 


\section{Hasil Analisis Linear Berganda}

\section{Tabel 5. Hasil Analisis Linear Berganda}

\begin{tabular}{|c|c|c|c|c|}
\hline $\begin{array}{l}\text { Dependent Varial } \\
\text { Method: Panel Le } \\
\text { Date: } 05 / 17 / 20 \\
\text { Sample: } 201520 \\
\text { Periods included: } \\
\text { Cross-sections in } \\
\text { Total panel (balar }\end{array}$ & $\begin{array}{l}\text { ares } \\
41 \\
27 \\
\text { servations: } 1\end{array}$ & & & \\
\hline Variable & Coefficient & Std. Error & t-Statistic & Prob. \\
\hline C & -0.194452 & 0.214288 & -0.907433 & 0.3663 \\
\hline CR & 0.000108 & 0.021146 & 0.005122 & 0.9959 \\
\hline DAR & 1.505895 & 0.313076 & 4.810006 & 0.0000 \\
\hline TATO & -0.142912 & 0.096515 & -1.480726 & 0.1417 \\
\hline
\end{tabular}

Effects Specification

\begin{tabular}{|c|c|c|c|}
\hline R-squared & 0.794019 & Mean dependent var & 0.240583 \\
\hline Adjusted R-squared & 0.737129 & S.D. dependent var & 0.365607 \\
\hline S.E. of regression & 0.187451 & Akaike info criterion & -0.317473 \\
\hline Sum squared resid & 3.689459 & Schwarz criterion & 0.328143 \\
\hline Log likelihood & 51.42945 & Hannan-Quinn criter. & -0.055113 \\
\hline F-statistic & 13.95707 & Durbin-Watson stat & 2.397023 \\
\hline Prob(F-statistic) & 0.000000 & & \\
\hline
\end{tabular}

Sumber data: Hasil pengelolaan menggunakan Eviews 9

\section{Hasil Uji-F}

\section{Tabel 6. Hasil Uji-F}

Dependent Variable: ROE

Method: Panel Least Squares

Date: $05 / 17 / 20$ Time: $13: 44$

Sample: 20152019

Periods included: 5

Cross-sections included: 27

Total panel (balanced) observations: 135

\begin{tabular}{crrrr}
\hline \hline Variable & Coefficient & Std. Error & t-Statistic & Prob. \\
\hline \hline C & -0.194452 & 0.214288 & -0.907433 & 0.3663 \\
CR & 0.000108 & 0.021146 & 0.005122 & 0.9959 \\
DAR & 1.505895 & 0.313076 & 4.810006 & 0.0000 \\
TATO & -0.142912 & 0.096515 & -1.480726 & 0.1417 \\
\hline \hline & Effects Specification & \\
\hline \hline
\end{tabular}


Cross-section fixed (dummy variables)

\begin{tabular}{llll}
\hline \hline R-squared & 0.794019 & Mean dependent var & 0.240583 \\
Adjusted R-squared & 0.737129 & S.D. dependent var & 0.365607 \\
S.E. of regression & 0.187451 & Akaike info criterion & -0.317473 \\
Sum squared resid & 3.689459 & Schwarz criterion & 0.328143 \\
Log likelihood & 51.42945 & Hannan-Quinn criter. & -0.055113 \\
F-statistic & 13.95707 & Durbin-Watson stat & 2.397023 \\
\cline { 1 - 1 } Prob(F-statistic) & 0.000000 & & \\
\hline \hline
\end{tabular}

Sumber data: Hasil pengelolaan menggunakan Eviews 9

Dari gambar tabel diatas terdapat hasil $F$-statistic pada penelitian ini yakni sebesar 0,000000 yang memiliki arti bahwa nilai $F$-statistic $<0,05$ atau kecil dari 0,05 sehingga dapat disimpulkan bahwa seluruh variabel independen atau variabel bebas dalam penelitian ini yang mencakup current ratio, debt to total assets, dan total assets turnover memiliki pengaruh yang signifikan terhadap profitability.

\section{Hasil Uji-T}

Dependent Variable: ROE

Method: Panel Least Squares

Date: 05/17/20 Time: 13:44

Sample: 20152019

Periods included: 5

Cross-sections included: 27

Total panel (balanced) observations: 135

\begin{tabular}{lrlrr}
\hline \hline \multicolumn{1}{c}{ Variable } & Coefficient & Std. Error & t-Statistic & Prob. \\
\hline \hline C & -0.194452 & 0.214288 & -0.907433 & 0.3663 \\
DAR & 0.000108 & 0.021146 & 0.005122 & 0.9959 \\
TATO & 1.505895 & 0.313076 & 4.810006 & 0.0000 \\
& -0.142912 & 0.096515 & -1.480726 & 0.1417 \\
\hline \hline & Effects Specification & & \\
\hline \hline & & & \\
Cross-section fixed (dummy variables) & & 0.240583 \\
\hline \hline & & & \\
R-squared & 0.794019 & Mean dependent var & \\
Adjusted R-squared & 0.737129 & S.D. dependent var & 0.365607 \\
S.E. of regression & 0.187451 & Akaike info criterion & -0.317473 \\
Sum squared resid & 3.689459 & Schwarz criterion & 0.328143 \\
Log likelihood & 51.42945 & Hannan-Quinn criter. & -0.055113 \\
F-statistic & 13.95707 & Durbin-Watson stat & 2.397023 \\
Prob(F-statistic) & 0.000000 & & \\
\hline \hline
\end{tabular}

Sumber data: Hasil pengelolaan menggunakan Eviews 9

Current ratio pada tabel tersebut menunjukkan nilai signifikansi sebesar 0,9959, artinya $>0,05$, sehingga current ratio tidak memiliki pengaruh yang signifikan terhadap variabel terikat yakni profitabilitas pada penelitian ini. Debt to total assets pada tabel tersebut menunjukkan nilai signifikansi sebesar 0,0000, artinya $<0,05$, sehingga debt to total assets memiliki pengaruh yang signifikan terhadap variabel terikat yakni profitabilitas pada penelitian ini. Total assets turnover pada tabel diatas menunjukkan nilai signifikansi sebesar 0,1417, artinya > 0,05, sehingga total assets turnover tidak memiliki pengaruh yang signifikan terhadap variabel terikat yakni profitabilitas pada penelitian ini. 


\section{Hasil Uji Koefisien Determinasi $\left(\mathbf{R}^{2}\right)$}

\section{Tabel 8. Hasil Uji Koefisien Determinasi $\left(\mathbf{R}^{2}\right)$}

\begin{tabular}{|c|c|c|c|c|}
\hline \multicolumn{5}{|c|}{$\begin{array}{l}\text { Dependent Variable: ROE } \\
\text { Method: Panel Least Squares } \\
\text { Date: } 05 / 17 / 20 \text { Time: } 13: 44 \\
\text { Sample: } 20152019 \\
\text { Periods included: } 5 \\
\text { Cross-sections included: } 27 \\
\text { Total panel (balanced) observations: } 135\end{array}$} \\
\hline \multicolumn{5}{|c|}{ Variable $\quad$ Coefficient $\quad$ Std. Error t-Statistic Prob. } \\
\hline C & 194452 & 0214288 & 9074 & \\
\hline $\mathrm{CR}$ & 0.000108 & 0.021146 & 0.005122 & 0.9959 \\
\hline DAR & 1.505895 & 0.313076 & 4.810006 & 0.0000 \\
\hline TATO & -0.142912 & 0.096515 & -1.480726 & 0.1417 \\
\hline \multicolumn{5}{|c|}{ Effects Specification } \\
\hline \multicolumn{5}{|c|}{ Cross-section fixed (dummy variables) } \\
\hline \multirow{7}{*}{ 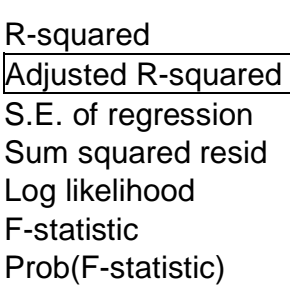 } & 0.794019 & \multirow{2}{*}{\multicolumn{2}{|c|}{ Mean dependent var }} & \multirow{2}{*}{$\begin{array}{l}0.240583 \\
0.365607\end{array}$} \\
\hline & 0.737129 & & & \\
\hline & 0.187451 & \multicolumn{2}{|c|}{ Akaike info criterion } & \multirow{5}{*}{$\begin{array}{r}-0.317473 \\
0.328143 \\
-0.055113 \\
2.397023\end{array}$} \\
\hline & 3.689459 & \multicolumn{2}{|c|}{ Schwarz criterion } & \\
\hline & 51.42945 & \multicolumn{2}{|c|}{ Hannan-Quinn criter. } & \\
\hline & 13.95707 & \multirow{2}{*}{\multicolumn{2}{|c|}{ Durbin-Watson stat }} & \\
\hline & 0.000000 & & & \\
\hline
\end{tabular}

Sumber data: Hasil pengelolaan menggunakan Eviews 9

\section{DISKUSI}

\section{Pengaruh Current Ratio terhadap Return on Equity}

Variabel independen yakni current ratio pada penelitian ini tidak memiliki pengaruh yang signifikan terhadap profitabilitas yang terdapat diperusahaan manufaktur sektor consumer goods periode 2015-2019 yang terdaftar di Bursa Efek Indonesia. Hasil dari penelitian ini tidak sama dengan penelitian yang dilakukan oleh Waleed, et al (2016:7), Janjua, et al (2016:9), Pradhan dan Gautam (2019:65), Fidanoski, et al (2016:357), Nanda dan Panda (2017:79), Sunjoko dan Arilyn (2016:83) hasil penelitian mereka menyatakan bahwa terdapatnya hubungan yang signifikan antara current ratio terhadap profitabilitas. Tetapi hasil pada penelitian ini didukung oleh penelitian yang dilakukan oleh Latha dan Rao (2017:1270), Alarussi dan Alhaderi (2017:453), Ezirim, et al (2018:106), AlAli, et al (2019:36), Alshatti (2016:89), dan Nurdin, et al (2016:303) yang menyatakan jika current ratio tidak memiliki pengaruh yang signifikan terhadap profitabilitas. Alarussi dan Alhaderi berpendapat bahwa profitabilitas tidak bergantung kepada current ratio pada sektor tertentu, current ratio berpengaruh terhadap profitabilitas hanya pada lembaga keuangan.

\section{Pengaruh Debt to Total Assets terhadap Return on Equity}


Variabel independen yakni debt to total assets memiliki pengaruh yang signifikan serta positif dilihat dari coefficient terhadap return on equity atau profitabilitas yang terdapat pada perusahaan manufaktur sektor consumer goods periode 2015-2019 yang terdaftar di Bursa Efek Indonesia. Hasil dari penelitian ini tidak sama dengan penelitian yang dilakukan oleh Pervan dan Mlikota (2012:283), Alarussi dan Alhaderi (2017:453), Latha dan Rao (2017:1270) yang menyatakan jika debt to total assets memiliki pengaruh yang signifikan negatif terhadap profitabilitas, Ezirim, et al (2018:104) dan Harisa, et al (2019:195) bahwa tidak terdapatnya pengaruh debt to total assets terhadap profitabilitas. Namun penelitian ini didukung atau sama dengan penelitian yang dilakukan oleh AlAli, et al (2019:36), Fidanoski, et al (2016:357), Alshatti (2016:89), Nurdin, et al (2016:303). Disaat ekonomi baik, maka leverage yang tinggi pada suatu perusahaan akan memiliki peluang untuk mendapatkan keuntungan yang lebih besar dan juga mempengaruhi keberlangsungan hidup perusahaan.

\section{Pengaruh Total Assets Turnover terhadap Return on Equity}

Variabel independen yakni total assets turnover pada penelitian ini tidak memiliki pengaruh yang signifikan terhadap variabel dependen yakni profitabilitas yang terdapat pada perusahaan manufaktur sektor consumer goods periode 2015-2019 yang terdaftar di Bursa Efek Indonesia. Hasil dari penelitian ini berbeda dengan penelitian yang dihasilkan oleh Latha dan Rao (2017:1270) mengatakan bahwa total assets turnover memiliki hubungan yang signifikan dan negatif terhadap profitabilitas, Alarussi dan Alhaderi (2017:452), Behera dan Das (2019:14) mereka menyatakan bahwa adanya hubungan yang positif serta signifikan antara total assets turnover terhadap profitabilitas perusahaan. Hasil penelitian ini sejalan dengan penelitian yang diteliti oleh AlAli, et al (2019:36), Sunjoko dan Arilyn (2016:83), serta Pervan dan Mlikota (2012:283) mereka menyatakan bahwa tidak terdapatnya pengaruh yang signifikan antara total assets turnover terhadap profitabilitas pada perusahaan.

\section{PENUTUP}

Pada penelitian yang diteliti ini, peneliti mempunyai keterbatasan yang di dapat, yakni sampel yang digunakan sebagai subjek pada penelitian ini hanya menggunakan perusahaanperusahaan manufaktur yang terdapat pada sektor consumer goods sekaligus terdaftar di Bursa Efek Indonesia (BEI), periode yang diteliti hanya selama 5 tahun, yakni pada tahun 2015 hingga 2019, peneliti hanya meneliti 3 variabel terhadap profitabilitas perusahaan yakni current ratio, debt to total assets ratio, dan total assets turnover, peneliti tidak mampu meneliti seluruh variabel yang yang mampu mempengaruhi profitabilitas dikarenakan keterbatasan waktu. Saran yang dapat dijadikan tolak ukur atau bahan pertimbangan terhadap peneliti berikutnya menambahkan jumlah sampel yang lebih luas, diharapkan kepada peneliti berikutnya untuk tidak cuma menggunakan subjek perusahaan manufaktur sektor consumer goods, melainkan menggunakan perusahaan manufaktur disektor yang berbeda, peneliti berikutnya diharapkan menambah variabel independen lain untuk memberikan pertimbangan kepada pihak manejer perusahaan berkaitan dengan faktor yang memiliki dampak terhadap profitabilitas.

\section{DAFTAR PUSTAKA}

Alali, M. S., Alsalem, A. S., Alawadhi, K. M., Alforaih, E. O., \& Alsabah, A. M. (2019). EXAMINING THE NEXUS BETWEEN INTERNAL FACTORS AND PROFITABILITY OF INSURANCE COMPANIES LISTED AT KUWAIT. 8(1), 30-38.

Alarussi, A. S., \& Alhaderi, S. M. (2018). Factors affecting profitability in Malaysia. Journal of Economic Studies, 45(3), 442-458. 
Alshatti, A. S. (2016). Determinants of banks' profitability - The case of Jordan. Investment Management and Financial Innovations, 13(1), 84-91.

Anderson, D. R., Sweeney, D. J., \& Williams, T. A. (2011). Statistics for Business and Economics, Eleventh Edition. South-Western: Cengage Learning.

Basuki, A. (2012). "Analisis Pengaruh Cash Ratio, Debt to Total Assets Ratio, Debt Equity Ratio, Return on Assets, dan Net Profit Margin Terhadap Dividend Payout Ratio." Skripsi. Universitas Diponegoro. Semarang.

Behera, B., \& Das, A. (2019). Management efficiency and profitability: A Case study of Petrochemical Industry. International Journal of Advanced Scientific Research and Management, 4(8), 7-16.

BEI (2020). Bursa Efek Indonesia. Retrieved Mei, 2020, from www.idx.co.id.

Berzkalne, I., \& Zelgalve, E. (2014). Trade-Off Theory Vs. Pecking Order Theory - Empirical Evidence From the Baltic Countries. Ekonomski i Socijalni Razvoj, 1(1), 22-32.

Bonna, A., Committee, R., Chairperson, C., Management, A., Faculty, D. S., Member, C., Management, A., Faculty, D. S., Management, A., Faculty, D. S., Officer, C. A., \& Riedel, E. (2012). Walden University.

Ezirim, C. B., Eniekezimene, D., Ali, O. U., \& Elike, U. (2018). Company-specific correlates of corporate profitability: Evidence from quoted insurance companies in Nigeria. African Journal of Business and Economic Research, 13(1), 81-113. https://doi.org/10.31920/company-specific_correlates_of_corporate_profitability

Fadli, F. (2020). CAN FINANCIAL RATIO CHANGE STOCK PRICE ? ( LQ 45 INDEX CASE STUDY FOR 2010-2018 ). International Journal of Information, Business and Management, 12(2).

Fidanoski, F., Choudhry, M., Davidović, M., \& Sergi, B. S. (2018). What does affect profitability of banks in Croatia? Competitiveness Review, 28(4), 338-367.

Hanifah. (2013). PENGARUH STRUKTUR CORPORATE GOVERNANCE DAN FINANCIAL INDICATORS TERHADAP KONDISI FINANCIAL DISTRESS ( Studi Pada Perusahaan Manufaktur yang Terdaftar di Bursa. Diponegoro Journal of Accounting, 2, 1-15.

Husna, A., \& Satria, I. (2019). Effects of Return on Asset, Debt To Asset Ratio, Current Ratio, Firm Size, and Dividend Payout Ratio on Firm Value. International Journal of Economics and Financial Issues, 9(5), 50-54.

IDN Financials (2020). IDN Financials. Retrieved Mei, 2020, from www.idnfinancials.com.

Janjua, A. R., Asghar, A., Munir, U., Raza, A., Akhtar, N., \& Shahzad, K. (2016). Influence of Liquidity on Profitability of Cement Sector: Indication from Firms Listed in Pakistan Stock Exchange. 6(5), 1-12.

Kalra, R. (2013). Mergers and Acquisitions: An Empirical Study on the Post-Merger Performance of Selected Corporate Firms in India. Business and Economics-Management, 7-67.

Kesdu, P., Cipto, A., Choerudin, A., \& Suryanti, Y. (2019). the Factors That Affecting Structure Capital in Manufacturing Companies: the Study in Indonesia of. International Journal of Information, Business and Management, 11(3), 227-235.

Kishore, K. (2008). Ratio and Leverage Ratio: An Empirical Study of Indian Public Sector Banks. 6(2), 20-28.

Latha, M., \& Rao, S. N. (2017). Determinants of profitability: Evidence from listed companies in the bse-fmcg. International Journal of Economic Perspectives, 11(3), 1264-1272.

Nanda, S., \& Panda, A. K. (2018). The determinants of corporate profitability: an investigation of Indian manufacturing firms. International Journal of Emerging Markets, 13(1), 66-86.

Pradhan, R. S., \& Shrestha, D. (2017). Impact of Liquidity on Bank Profitability in Nepalese 
Commercial Banks. SSRN Electronic Journal, 57-67.

Rizqia, D. A., Aisjah, S., Program, P., \& Java, E. (2013). Effect of Managerial Ownership , Financial Leverage, Profitability, Firm Size, and Investment Opportunity on Dividend Policy and Firm Value. 4(11), 120-130.

Rudin, M., Nurdin, D., \& Fattah, V. Y. (2016). The Effect of Liquidity and Leverage on Profitability of Property and Real Estate Company in Indonesian Stock Exchange. International Journal of Social Sciences and Management, 3(4), 300-304.

Sunjoko, I. M., \& Arilyn, J. E. (2016). Effects Of Inventory Turnover, Total Asset Turnover, Fixed Asset Turnover, Current Ratio And Average Collection Period On Profitability. Jurnal Bisnis Dan Akuntansi, 18(1), 79-83.

Waleed, A., Pasha, A. T., \& Akhtar, A. (2016). Exploring the impact of liquidity on profitability: Evidence from banking sector of Pakistan. Journal of Internet Banking and Commerce, 21(3).

Yazdanfar, D. (2013). Profitability determinants among micro firms: Evidence from Swedish data. International Journal of Managerial Finance, 9(2), 151-160. 